\title{
Impact of Organizational Communication on Organizational Citizenship Behavior and Job Satisfaction: Research Findings
}

\author{
B. Siva Naga Devi ${ }^{1}$, Dr.M.Kamaraj ${ }^{2}$, Dr. Ravi Prakash.K ${ }^{3}$ \\ ${ }^{1}$ Research Scholar, Department of Business Administration, Annamalai University, Chidambaram, Tamil Nadu \\ ${ }^{2}$ Associate Professor, Department of Business Administration, Annamalai University, Chidambaram, Tamil Nadu \\ ${ }^{3}$ Associate Professor, Department of IMBA, Vishwa Vishwani School of Business, Hyderabad
}

\begin{abstract}
Communication play a vital role at all levels of organization. It affects employee commitment level, Citizenship behavior and job satisfaction levels of employees. The purpose of this study is to understand and assess how organizational communication effects organizational citizenship behavior and Job satisfaction levels. Data was collected from 85 software employees working at different levels by using close ended questionnaire. It was concluded that organizational communication has direct and positive relationship with employee Job satisfaction among software employees. The analysis further proven that organizational citizenship behavior as a mediator further weakens the relationship between organizational communication and job satisfaction. Although much previous research is existed in association of organizational communication, Organizational citizenship behavior and job satisfaction, but this is of first known attempt to assess mediating effect of OCB in relation with other variables.
\end{abstract}

\section{Keywords}

Organizational Communication (OC), Organizational Citizenship Behavior (OCB), Job Satisfaction(JS)

\section{Introduction}

Communication is an integral part of management practices. According to Mintzberg, 1973, Managers spend 80 percentage of their official time in communicating about organizational activities. Several researches in the past are evident to this fact. A study by Yammarino et al,1988, explained significant relationship between amount of time spent in communication at work and outcome. As a result of many of these kind of findings, several modern organizations invested significant amount of resources in developing an effective communication system both internal and external, to facilitate proper and relevant communication among employees and stake holders at different levels within and also outside the organization respectively.

The purpose of this study is to provide further insight into the relationship between Organizational communication satisfaction, Organizational citizenship behavior and Job satisfaction. Especially researchers intend to test the hypothesis that communication satisfaction in organization results in organizational citizenship behavior and job satisfaction. This study is focused on IT sector at Hyderabad nd on Software employees in particular.
Employees of Software Companies confront many challenges while communicating at workplace with peers, team leaders, project managers etc. In software companies, employees deal with companies in multi nations which demand them to work out of standard hours. This is not an exception to middle and top managers. These dichotomous schedules arise stress, confusion and also communication gaps between people operating. Secondly, software companies are equipped with multi lingual people who belong to different locations geographically, which leads to many communication issues among employees that effects their job satisfaction and behavior. Thirdly, software companies operate usually in matrix organizational structures, where they are accountable for more than one superior, which makes it a complex task to communicate. All these factors, synergistically, affect the extent to which software employees actively engage in meaningful internal organizational communication. According to (Casico,2000) this can also lead to a sense of isolation among these employees from others in organization leads to poor organizational citizenship behavior and job satisfaction. 


\section{Literature Review}

From the beginning of twentieth century lot of research has been emerged in the field of Organizational communication which resulted in a large body of literature in this field. Despite of large body of research, still many questions in this subject are un-answered because of increasing complexity in modern organization, their diverse environment in which they operates, dynamism, information technology advances, change in employee life styles both professionally and personally (Jules \& Christopher ,2009 \& Be' Langer et al, 2006). While many dimensions of employee behaviors in relation with organizational communication are examined, some of them are more significant that effect employee attitudes, perceptions which in turn affect employee performance. One of the most important relationships between organizational communication and work attitude is that involving job satisfaction. One more current and less explored relationship is between organizational citizenship behavior and organizational communication. Organizational citizenship behavior and Job satisfaction are two important work place attitudes that are discussed predominantly in literature. This is because, an employee's performance depends upon his work place attitudes like organizational commitment (Spector et al. 2006), Organizational citizenship behavior (Cohen et al, 1999) and Job satisfaction and Performance (Freund et al,2004).

\section{Communication Practices and Job Satisfaction:}

An organization consists of full spectrum of communication activities that enable them to conduct their operations both inside and outside the organization, at formal and in formal level. This particular study concentrated on internal practices of communication that enable employees to communicate horizontally, vertically and diagonally. In this context, organization has a vital role to provide effective platform within organization that enable employees to communicate effectively and efficiently with timely, relevant and reliable information.

Effective Communication practices do affect the employee attitude and outcome factors of the organization (White et al, 1981). Communication Dimensions include Communication Climate, Communication with supervisor, Organizational integration, Media Quality, Horizontal and Informal Communication, Organizational Perceptive,

H2: Organizational Communication will be significantly and positively related to Organizational Citizenship behavior.
Personal Feedback and Communication with sub- ordinates (Downs \& Hazen, 1977). Ample Communication efforts help in shaping employee attitude and positively affects organizational outcome (Hargie, 2002). According to Zimmerman et al, 1996 employees always quest for more information form their organization than what they usually receive. Both the studies revealed importance of internal communication in the organization. Even though timely, reliable and proper channels are important, it is equally important to see that, employees will not be overloaded with information. Effectiveness of Organizational communication needs to assessed through number of factors like channels of communication, Reliability of information, quality of information and like factors (Pincus, 1986). Employees whose communication needs are satisfied reported to be satisfied with their job situations (Goris, 2007). A part form communication with supervisor, other factors like communication climate, personal feed back also reportedly related to job satisfaction. Organizational communication and job satisfaction are concepts that are vital to management experts and investigators (Bulutlar et al , 2008), due to the point that worth of communication and job satisfaction may define productivity, work-life balance and eventually define the level of output (Pettit et al, 1997).

\section{H1: Organizational Communication is significantly and positively related to Job satisfaction.}

\section{Communication Practices and Organizational Citizenship behavior:}

Organizational Citizenship is defined as a "Behavior that is discretionary, not directly or explicitly recognized by the formal reward system, and that in the aggregate promotes the effective functioning of an organization." Devi (2019), in her research stated that Organizational Citizenship Behavior (OCB) has significant relationship with Communication. Effective and Efficient practice of organizational communication will increase organizational citizenship behavior in a better direction. According to Balino et al (2003), Organizational citizenship behavior is important to support organizational effectiveness in the long run. It is linked with level of wellbeing or uneasiness associated to the internal state of a worker (Bandurs \& Lyons , 2012). A study by Chou et al., (2012) Illinois have found that there is a significant association between OCB and job satisfaction of an employee.

H3a: Organizational Citizenship behavior will be positively and significantly related with Job satisfaction.

H3b: Organizational Citizenship behavior has positive mediating effect on the relationship between 
organizational communication and level of job satisfaction.

Despite the importance attributed to concepts, organizational communication, Organizational citizenship behavior and job satisfaction, little is known about the relationship between them. Only few studies published their relationship especially, Organizational citizenship behavior is studied as resultant of job satisfaction (Varona et al 2006). But in the present study, researchers studying Organizational Citizenship Behavior, as causing factor and mediating variable of Organizational communication and Job Satisfaction.

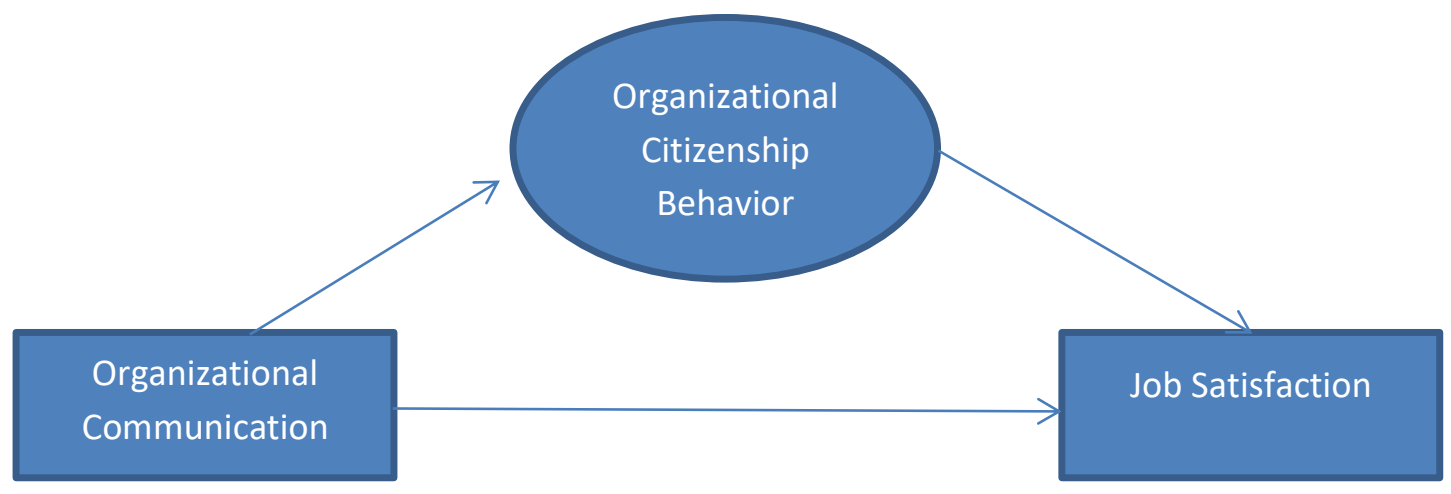

Figure 1: Conceptual Frame Work

\section{Methodology}

\section{Sample}

The focus of this study is on Software Employees working in Hyderabad City. As per the Telangana State government reports, there are 1,50,000 Software employees working in more than 600 IT companies. Authors have forwarded a structured questionnaire to 100 software employees randomly as a part of pilot study, out of which 85 completely filled Google forms returned. Majority of respondents are male (61.2\%, S.D: 0.49), Married (60\%: S.D: 0.49), majority of them are between $30-40$ years (72.9\%, S.D: 0.77) of age and major part of employees qualification is B. Tech (42 \%, S.D: 1.384)

\section{Measures}

The study questionnaire for this study especially organizational communication scale is developed by researchers consists of pre- existing work related measures. Only quantitative data is collected and considered.

Organizational Communication Practices: To develop a communication scale to asses' software employees Communication levels and their satisfaction level researchers have gone through Standard scales like Downs \& Hazen,1977, Goldhaber, 1979 \& Robins Model ,2015 etc. Each of these scales is standardized by considering different factors related to their studies. In order to get completeness for the scale researchers basing on internal operating structures in software companies. Factors that are chosen for this scale are

1. Interpersonal Trust

2. Communication Channels

3. Communication Climate

4. Quality of Information

5. Direction of Communication'

6. Reliability of Information

7. Feedback \& Satisfaction

A part from Standard scales mentioned above many other scales used by different researchers in their respective studies were referred. Responses for all selected sub scales were measured using 5 point likert scale. For Interpersonal Trust, Options are scored as, 1.Very Little 2.Little 3. Average 4. To Some Extent 5. To a Great Extent. For Communication Channels Options are scored as 1.Almost Never 2. Never 3.Frequently 4. Very frequently 5. Almost Always. Remaining Sub-factors options are scored as

1.Strongly Agree 2. Agree 3. Neutral 4. Agree 5. Strongly Agree. Cronbach Alpha values of the dimensions of the scale are:.898, .802, .899, .862, .942,.881 \& .958 respectively, which shows that scale has high internal consistency.

Organizational Citizenship Behavior: Researchers adopted Podsakoff \& MacKenzie (1990) scale to assess citizenship behavior of organizational employees. This scale contains Five measures and 18 expressions. Five measures 
of the scale are Altruism (Voluntary behavior of employees to help their colleagues), Courtesy (Employees readily taking advice from their colleagues on decision making), Sportsmanship (Employee not complaining about organizational problems), Conscientiousness (Employee fulfilling organizational expectation) \& Civic Virtue (Employee Voluntary behavior to adopt to organizational changes). All the subscales are measured 1. Strongly disagree 2. Disagree 3.Neutral 4. Agree 5.Strongly Agree, except Sportsmanship, which is scored in reverse to increase the reliability and validity of the scale. Cronbach Alpha values of the dimensions of the scale are:.863,.874,.958,.825 \& .792 respectively, which shows that scale has internal consistency.

\section{Job Satisfaction:}

Hackman \& Oldham's (1975), 14 item scale was adopted for the purpose of this study by researchers. It doesn't have any sub scales and Alpha value of this scale is 0.948 . Statements in this scale are prepared in 5 point Likert scale and choice strongly Agree is designated as giving 5 and Strongly disagree as giving 1 points. Accordingly, a high point taken in anysize figures that the worker finds communication effective in respect of the related dimension and a low point figures an opposite situation.

\section{Control Measures:}

Respondents were asked to provide information related to 6 demographic variables
1. Gender
2. Age
3. Marital Status
4. Work Experience
5. Monthly Income
6. Designation

\section{Results}

The Central questions of this study are:

1. Whether organizational citizenship behavior mediates the relationship between Organizational communication and Job satisfaction

2. Whether Organizational Communication effects Job satisfaction of an employee or not.

While number of approaches and connected methodologies available for testing mediation, "causal steps approach" was chosen by us (Mackinnon et al., 2002). It was first introduced by Judd et al in 1981 and later advanced by Baron et al in 1986, which is the most commonly used approach in the psychological literature (Mackinnon et al., 2002). Mediation testing is three-stage process. In I stage, Bivariate analysis is applied to establish the association between study variables. In order to support a hypothesis of mediation, the correlation between the independent and the dependent variables, and correlation between mediator and the dependent variables, must be significant. If this condition is satisfied, then the second step can be considered. In stage 2, Regression Analysis is performed: firstly, the mediator is regressed on the independent variable; secondly, the dependent variable is regressed on the independent variable; and then lastly, the dependent variable is regressed on both the independent variable and the mediator (Baronet al, 1986; Judd et al, 1981). Further support for a mediation hypothesis exists only if the independent variable affects the mediator in the first equation; the independent variable affects the dependent variable in the second equation; and the mediator affects the dependent variable in the third equation (Baron et al, 1986). Finally, in $3^{\text {rd }}$ stage, the effect of the independent variable and the mediator on the dependent variable is checked. If mediation is present, the effect of the independent variable on the dependent variable will be less in the third regression analysis than in the second (Baron et al, 1986). Full mediation is present if "the independent variable has no effect when the mediator is controlled for" (Baron et al, 1986). 
behavior demonstrated a positive correlation with dependant variable job satisfaction $(0.427, \mathrm{p}<0.001)$.

\section{Regression Analysis:}

Table- II shows the results of Regression Analysis. The results indicated that Organizational Communication has strong positive impact on Job satisfaction ( $\beta=$ $.576, \mathrm{p}<0.001)$, thus accepting Hypothesis 1 that Organizational Communication is positively and significantly related with job satisfaction of software employees in Hyderabad.

The relationship of Organizational Communication with Organizational citizenship behavior is also significant $(\beta=$ $.442, \mathrm{p}<0.001$ ), thus accepting Hypothesis 2 (i.e.,) Organizational Communication is significantly and positively related with Organizational citizenship behavior.

Regression Analysis further to point that Organizational Citizenship has positive impact on Job satisfaction $(\beta=.446$, $\mathrm{p}<0.001$ ), hence proving Hypothesis $3 \mathrm{a}$ that Organizational Citizenship Behavior has positive and significant impact on Job satisfaction.

Finally the results of Moderated Regression Analysis showed weaken the relationship between Organizational Communication and Job satisfaction $(\beta=0.237, \mathrm{p}=0.019)$ $(\mathrm{p}>0.001(\mathrm{NS})$ ) rejecting Hypothesis $3 \mathrm{~b}$ that, Organizational Citizenship behavior will mediate the relationship between organizational communication and level of job satisfaction.

\section{Discussions}

In this study it is observed that hypothesis of all direct relationships are supported by findings. Organizational Communication has positive and significant impact on job satisfaction, which indicated that when employees are communicated well about their roles, duties and responsibilities, their job satisfaction level increases as they can perform well. These findings are in congenial with studies of Giri et al (2010) that organizational communication has significant positive impact on Job performance and job satisfaction.

Results also supported that Organizational communication has positive impact on Organizational citizenship behavior. When employees are well informed about their roles time to time and about organizations interest in retaining them and performance levels, this for sure have a positive mark on their level of attachment towards organization and employees owns organization. These results are going with
Ann (2017) that Organizational Citizenship behavior is positively related with Organizational Communication.

Hypothesis also supported the findings that Organizational Citizenship Behavior has a positive relationship with Job Satisfaction of software Employees. It is observed that employees when they feel attached to their work, they contribute more than what they are supposed to be, which in turn increase their job satisfaction. Osman (2014) supports the findings of the study he argued that quality of communication effects Organizational Citizenship behavior and which in turn influence job satisfaction. When the mediating role of organizational citizenship behavior was tested with the organizational communication and job satisfaction, the result does not support the hypothesis which was made. It was predicted that organizational citizenship behavior strengthens the relationship between organizational communications, job satisfaction. But the results indicate that Organizational citizenship behavior weakens the relationship between organizational communication and job satisfaction. This result point out that OCB can be taken as an important aspect of Organizational Environment.

\section{Implication of Managers/Policy Makers}

This study provides valuable implications for managerial staff. As this study stresses the importance of citizenship behavior and its influence on improving the levels of job satisfaction. Policy makers must concentrate on developing HR policies that must successfully make employee to contribute beyond what he is expected in the way that improve the relationship between organizational communication and job satisfaction. From this study it can be understood that, how important is communication in getting desired output.

\section{Limitations and Recommendations for Future Research}

There are four limitations that need to be addressed in this study. Firstly, the methodology employed to test for mediation essentially that based on which important assumptions about the direction of the relationships between the variables under study. Though the data supports this study, more research will be desired to confirm a causal relationship. Secondly, this study was focused on employees of software industry in Hyderabad and additional research is necessary to generalize the relationship between variables to other types of organizations. Thirdly, population of this study represented a fairly homogeneous group of individuals in terms of both cultural and ethnic diversity, in this case additional research is needed to determine if the findings can be generalized to across cultural and racial boundaries. 
Finally, the sample size for this study was relatively small (n $=85$ ); future, large-scale research will be instrumental in determining whether these findings can be replicated. To conclude, this research has solely examined the relationship of communication satisfaction to job satisfaction, on the one hand, and organizational citizenship behavior, on the other.

\section{Conclusions}

Organizational Communication is one of the important factors that affect employee behavior in many aspects. Present study showed that, Organizational communication has positive impact both on organizational citizenship behavior and job satisfaction. Job satisfaction is ultimate result that an organization want its employees to attain, which will be influenced by organizational commitment, organizational citizenship behavior. Therefore organizations must try to achieve employee job satisfaction by carefully designing their communication patterns like, styles, channels and other factors which behavioral factors of employees get affected directly and in directly.

\section{References}

[1]. Bateman, T.S. and Strasser, S. (1984), "A longitudinal analysis of the antecedents of organizational commitment", Academy of Management Journal, Vol. 27 No. 1, pp. 95-112.

[2]. Becker, T.E. and Billings, R.S. (1993), "Profiles of commitment: an empirical test", Journal of Organizational Behavior, Vol. 14 No. 2, pp. 17790.

[3]. Be'langer, F. and Watson-Manheim, M.B. (2006), "Virtual teams and multiple media: structuring use to attain strategic goals", Group Decision and Negotiation, Vol. 15 No. 4, pp. 299-321.

[4]. Bentein, K., Vandenberg, R., Vandenberghe, C. and Stinglhamber, L. (2005), "The role of change in the relationship between commitment and turnover: a latent growth modeling approach", Journal of Applied Psychology, Vol. 90 No. 3, pp. 468-82.

[5]. Blau, G.J. (1986), "Job involvement and organizational commitment as interactive predictors of tardiness and absenteeism", Journal of Management, Vol. 12 No. 4, pp. 577-84.

[6]. Blau, G. and Boal, K. (1989), "Using job involvement and organizational commitment to predict turnover", Journal of Management, Vol. 15 No. 1, pp. 115-28.

[7]. Cohen, A. (1993a), "Work commitment in relation to withdrawal intentions and union effectiveness",
Journal of Business Research, Vol. 26 No. 1, pp. 75-90.

[8]. Cohen, A. (1993b), "Organizational commitment and turnover: a meta-analysis", Academy of Management Journal, Vol. 36 No. 5, pp. 1140-57.

[9]. Cohen, A. (1999), "The relation between commitment forms and work outcomes in Jewish and Arab culture", Journal of Vocational Behavior, Vol. 54 No. 3, pp. 371-91.

[10]. Cohen, A. (2000), "The relationship between commitment forms and work outcomes:a comparison of three models", Human Relations, Vol. 53 No. 3, pp. 387-417.

[11]. Pettit, J.D.J., Goris, J.R. and Vaught, B.C. (1997), "An examination of organizational communication as a moderator of the relationship between job performance and job satisfaction", Journal of Business Communication, Vol. 34 No. 1, pp. 8198.

[12]. Tetteh et al. (2012). Work environment and its impact on employee's performance. (Unpublished dissertation). Christian Service University College, Kumasi, Ghana.

[13]. Uzee, J (1999), the inclusive approach: creating a place where people want to work. Facility Management Journal of the International Facility Management Association, 26-30

[14]. Vischer, J. C. (2006). The effects of the physical environment on job performance: towards a theoretical model of workspace stress. Wiley Inter Science, DOI: 10.1002/smi.1134

[15]. Vischer, J.C. (1989). Environmental quality in offices. New York: Van Nostrand Reinhold 